\title{
Collaboration of vocational education between schools, universities and industry in Indonesia "The case of analytical chemistry schools and polytechnics under the Ministry of Industry"
}

\author{
Mufidah \\ The Center of Industrial Education and Training \\ Ministry of Industry \\ Jakarta, Indonesia \\ mmufidah@gmail.com
}

\begin{abstract}
University and industry collaborations are rapidly becoming a common practice worldwide as a response to the increased of competition resulted from globalization and constant technological advancement. This collaboration is mainly undertaken to enhance the diffusion of knowledge, increase research and development, patent innovations, create higher numbers of skillful and knowledgeable candidate workers. In order to extend the benefit of this collaboration, the collaboration should be designed by involving the vocational school due to their strategic position as skilled labor supplier for the industry. Therefore, the graduates will fulfill the job positions in the industry according to the required competence qualifications and finally encourage the development of the industry. The collaboration pattern between the analytical chemical vocational high schools (SMK, SMAK) and the polytechnics under the ministry of Industry (AKABO) in line with the development of the larger collaboration with the industry is analyzed here. Using qualitative descriptive method, the collaboration pattern among those institutions covers several layer, i.e. outcome, outputs, product, process by using national competency standard as basis. The form of collaboration were : 1 ) National competency standard (SKKNI) formation at mega/outcome level, 2) Curriculum based competencies (CBC) design and review, production based curriculum (industrial working practices, teaching factory) design, implementation and review at macro/outputs level, 3) Teacher/lecturer internship at macro/outputs level, and 4) Industry visitation, seminar, training, workshop, relationship with alumni who work in industry, employee competency test, and joint research and publication at process level. To meet the need for recognition of Indonesia Qualification Framework (IQF) at the CBC design, some materials that have been followed in SMK SMAK also recognized by AKABO a total of 20 credits.
\end{abstract}

Keywords: School-industry collaboration, polytechnicindustry collaboration.

\section{INTRODUCTION}

The economic growth target which become the aim of Indonesian government would be achieved by the growth of industrial sector. One of the industrial growth driver is the availability of competent workforce in accordance with industrial needs [25].

Nowadays, the availability of competent workers is still a main problem in Indonesia, there are many of graduates from Polytechnics can not be absorbed by the industry through labor market [25]. This leaded by the condition that $59 \%$ Polytechnic were still accredited under B. In order to solve this problem, collaboration between university and industry is a necessary. On the other side, the roles of vocational school (SMK SMAK) is also important in providing competent workforce mainly for operator level and technician level. Some facts tell that the industrial workforce from the vocational school is more favored by industry [28]. This is closely related with the technical competency offered by the vocational education graduates. Reference [6] said that SMAK graduates have excellent labor-market outcomes, and the chemical competence graduates has the skills needed by the market. Similar result is also showed by the survey conducted by SMK-SMTI [15].

In addition to the university and industry collaboration, vocational school should be considered to put in the collaboration. It is related with the minimum requirement of education level to fulfill the operator position in Indonesia is vocational secondary school (SMK) or general secondary school (SMU).

Because of the good relationship between vocational schools and universities as a supplier of industrial labor and also vocational relationship to the university when students continue their study, there should be a link between these three especially those having the same field. The pattern of collaboration among universities, vocational school and industries will makes the effectivity and efficiencies at the process by adjusting their learning to be in line and 
not overlapping to the needs of the industry. Thus, using this pattern, the graduates will be able to fulfill the job positions in the industry according to the required competence qualifications and finally encourage the development of the industry.

The Ministry of Industry (MoI) has actually initiated the collaboration with industry since 2012 by the first phase repositioning program in 2012, and currently has run the second phase reposition. This policy would have been influenced the collaboration among industry and vocational education institution, academy, university under the Ministry of Industry. The discussion how this collaboration taken place is interesting. It is aimed to make sure the high employment of industrial workforce.

The center of industrial education and training (CIET) with its duty in education and training oversees nine schools, nine polytechnics, one academy and seven training centers. There are three (3) vocational secondary school and one (1) polytechnic university level that specializes chemical analysis including the School of Chemical Analysis Bogor (SMAKBO), School of Chemical Analysis Padang (SMAKPA) and School of Chemical Analysis Makassar (SMAKMA) and Chemical Analysis Polytechnic Academy Bogor (AKABO).

Reference [16] uses educational result chain to explain how curriculum designed in Polytechnic. The stages in educational result chain are mega/outcomes, macro/ouput, micro/product, process and input. The regulation as external policies which influence the design at mega level is Indonesian Quality Framework (IQF). This research try to find educational result chain based on National Competency Standard (SKKNI) and how it influence to all stages. Because SKKNI made together with industry, this research also seek what kind of collaboration between education institution with industry in every stage of educational result chain.

The curriculum alignment between SMAK and AKA also need to discover to streamline the learning process.

\section{METHOD}

This research approach uses qualitative descriptive approach to the study sites at SMAKBO, SMAKPA, SMAKMA and AKABO. This method could be used to discover and understand something behind the phenomenon and it characteristics [7]. This is in accordance with the purpose of this study which will find what is required by the education institutions in collaboration with industry and how the relationship between these agencies in curriculum alignment to streamline the process of learning. Qualitative research, however, is more holistic and often involves a rich collection of data from various sources to gain a deeper understanding of individual participants, including their opinions, perspectives, and attitudes [7].
The data generated in this research is descriptive data obtained from the data in the form of writing, words and documents derived from sources or informants being researched and reliable. The source of information data obtained from Head of Development of Vocational Education and Vocational Industry, Head of Industrial Vocational Education Sub Division, Head of Industrial Human Resource Development Sub Division, Head of SMAKBO, Head of SMAKPA, Head of SMAKMA and Director of AKABO along with teachers and lecturers at the respective education institution.

\section{COLLABORATION PATTERN BETWEEN EDUCATION INSTITUTION AND INDUSTRY}

Collaboration can be defined as a form of integration with a high degree of horizontal integration but a low degree of vertical integration. This means that most integration is accomplished through voluntary agreements and mutual adjustments between the organisations involved [18]. This form of integration is based on a willingness to work together and it may be implemented through intensive contacts and communications between the different organisations. Inter-organisational collaboration allows organisations to constructively explore their differences and find solutions that go beyond their own limited visions of what is possible (Gray, 1989; Huxham, 1996 as cited in [18]). There are lots of barriers in establishing such an inter-organizational collaboration. According to many researches, the barriers can be managed by the organisations involved through formal agreements on rules, regulations and financial support (van Raak et al., 2003; Hultberg et al., 2003 as cited in [18]), and also can be diminished through long term partnership relationships [10]. Collaboration between academia and industry is increasingly a critical component of efficient national innovation systems. Developing countries face even greater barriers to such alliances, calling for a differentiated approach to promoting universityindustry collaboration [9]. By strengthening connections between education institutions and industry, it helps equip students with skills needed for successful recruitments. In this context, private firms can play multiple roles in supporting education institutions to maximize their contribution to education outcomes such as publishing learning materials and developing assessment tools and educational software, building and maintaining schools, and providing scholarships support for students [8].

The area of collaboration between education institution primarily lies in the area of curriculum as a key element for managing education process to meet the educational goals [16]. In this context, curriculum is an engine of educational accomplishment which should be planned strategically. This begins with an ideal vision from which an organization mission is derived. Strategic planning identifies results based upon an ideal vision. These results must be defined into measurable descriptions of knowledge, skills, 
attitude and abilities which are suitable for students in the future life. It has to link at three levels of achievements: societal (outcomes), organizational (output or completers/leavers), and individual or small group (products). Input and process are one of determinant factors which impact on outcomes of education [16]. This is inline with reference [13] identified four stages in establishing the universityindustry collaboration,i.e inputs, in-process activities, outputs, and outcomes.

This stage can be described as an educational result chain which shows the relationship between inputs and outcomes [19] at Fig. 1.

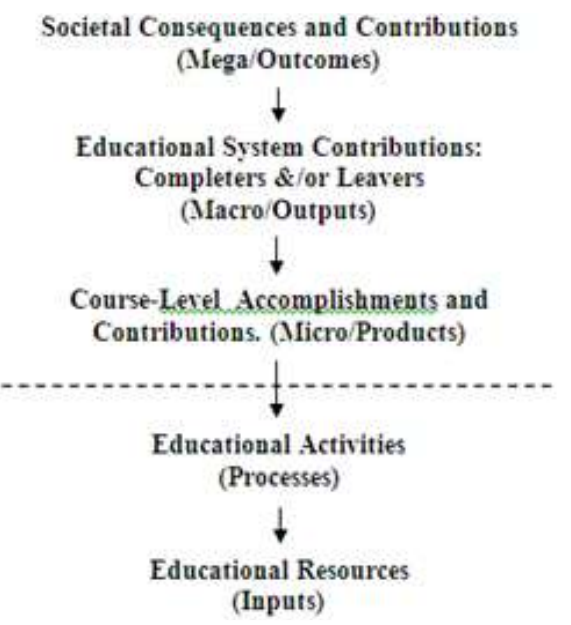

Ends

Means

Fig. 1. An Educational Result Chain [19]

Curriculum design and its implementation are influenced by the environment, such as educational policies (external and or internal) that directly influence the curriculum design at mega, macro, and micro levels.

According to above diagram, designing curriculum as a product of collaboration should consider the societal consequences and contribution at mega level/outcomes, such as matching with required standard competency of the industry. The goals of the curriculum development should be matched with the goals of industry. This condition opens the possibility of collaboration between education institution and industry. Creating the shared goals in this context is something interesting to discover. Moreover, in the macro level, the curriculum should be designed to convince the student can complete the required competence.

At micro level, professionalism of teachers, facilities, and methodology are the main factors that influence of educational results. Methodology relates to instructional design. According to reference [16], the performance approach is suitable for competencebased curriculum.

\section{EDUCATION INSTITUTION - INDUSTRY COLLABORATION PATTERN}

Cooperation between education institution under $\mathrm{MoI}$ and industry can be categorized as collaboration because of its horizontal integration character. Both parties have the willingness to work together and have voluntary agreements. Agreement between the two organizations occurred because of the need and interconnection between the them.

The collaboration relationship with the industry was developed by MoI with the aim to obtain inputs and information on curriculum development, getting internships for students and teachers, promoting graduates to be absorbed in the industry, and getting development of teaching materials, and reducing the cost of training for the prospective workforce [2]. Moreover, reference [1] and [2] drive the collaboration between education institution and industry should be developed in the Link \& Match that derived to the development of competency-based education.

Structural barriers to inter-organisational collaboration has been managed through preparation of National Competency Standard (SKKNI) and several Memorandum of Understanding (MoU) [22] and people/institution long term relationship. Collaboration has not reached the financial support because education is fully funded by state or international institutions such as Technical and Vocational Education and Training (TVET). In the preparation of the SKKNI, the industry is highly involved with other relevant stakeholders. For instance, the preparation of SKKNI for Chemical Analysis and Industrial Waste Processing involve 17 companies, 2 industry associations and 1 industrial region. On the other side, the Memorandum of Understanding (MoU) has been taken by the AKABO and industry in the area such as employee competence test in the company; training, seminar, workshop either for industrial employee or lecturer; research and publication in the area of curriculum development and applied research for advancing the industrial process.

While collaboration which is formed to all education institution and industry through $\mathrm{MoU}$ and long term relationship are curriculum design and review, training/seminar/workshop for student, industrial working practices, internship teacher/lecturer.

\section{A. Mega/outcome}

Mega/outcome level are influenced by external policies such as Indonesian Qualification Framework (IQF) [16] or National Competency Standard. IQF is the framework required by the Ministry of Research, Technology and Higher Education in measuring the competency standards of higher education graduates [17]. In addition, MoI also uses SKKNI to link and match between education institution and industry. SKKNI covers completed working ability (knowledge, skills and attitude) needed by graduates to work in industry. 
SKKNI which is used by SMAK \& AKA is the National Competency Standard Laboratory Testing Services (SKKNI Jasa Pengujian Laboratorium). This standard is adoption from the standard used in Australia (Australian Laboratory Operations Training Package (MSL09) [27]. Furthermore, AKABO also uses National Competency Standard of Chemical Analysis (SKN-KA) and SKKNI in the area of chemical analysis [27]. AKABO is also involved in the preparation of the two SKKNI together with other industry and stakeholders.

All this standard and framework regulation combined on the design of curriculum as an output of educational result chain. This approach is established in order to meet educational goals with industry needs.

\section{B. Macro/output}

Curriculum as a macro level policy (organizational) must be designed strategically to provide qualified education result. The curriculum design can be categorized to two concepts, i.e. curriculum based competency (CBC) and Production based curriculum (PBC). Based on the $\mathrm{CBC}$, the competency as learning outcomes is measured by some of indicators which describe knowledge, skills, attitudes and abilities that have been mastered by students after completing a course [16]. Furthermore, the $\mathrm{PBC}$ is designed by using a production process as a learning medium. The objective of this approach is primarily to introduce students to the real working environment (Depdiknas as cited at [24]).

In the $\mathrm{CBC}$, the curriculum is designed by educational institutions based on standard which are further validated, and reviewed by industry after being implemented. A review is part of the curriculum evaluation and development process. Education institution keep their curriculum updated with industry needs through various strategies, such as annual meetings between the school and the companies hosting student internships; periodic meetings with industries every year or every 4 year, usually represented by the business association; and internships for students and teachers at companies ([6]; [22]). The CBC development for the case can be explained as follows :

SMK/SMAK curriculum uses both curriculum the KTSP Curriculum 2006 and curriculum 2013 set by the Ministry of Education and Culture (Kemendikbud) [4] and then adapted to SKKNI laboratory testing services. All SMAKs have the same curriculum [3] with the difference is only at local content subject. While AKABO uses this 4 policies as the standard for their curriculum development.

The development of SMK curriculum should have an internal and external considerations. Externally, every curriculum development should consider its connection with universities, courses, and training in the industry, and others [24]. For instance, SMK/SMAK have an external connection with $\mathrm{AKABO}$ at the recognition to the same materials because of the demand of IQF [20].
IQF has been established as a rule since 2012, however there is no source has been found that explain about the iimplementation of mutual recognition of curriculum between vocational high school and vocational higher education in Indonesia.

Since 2015 some materials has been recognized between SMAK and AKA consisting of 20 credits of subjects including 5 theoretical material credits and 15 credits of practice materials [22]. In this way, programs duplication can be avoided and the efficiency can be improved. In addition, the "career ladder" of students can be smoothed without losing time [24]. Other benefit from this alignment is the existence of mutual recognition of the competency quality of graduates among education institutions under the MoI.

SMAK and AKA conducted a block system to study theory and practice [5] which designed based on each education institution need (student ability, availability of teacher/lecturer, easiness on scheduling, etc).

Furthermore, the PBC is designed with industrial working practices (Prakerin) in the industry and simulation in the school. Prakerin is a practical learning activity to apply, strengthen, and improve the competence of learners by involving an expert practitioners to strengthen learning practice by way of coaching [14]. The design of Prakerin made together between education institution with industry.

All students in education institution run Prakerin for 3-6 months. Industries that have cooperated with education institutions in prakerin are about 50 to 198 companies located in local and overseas ([12], [22]).

Especially for AKABO, Prakerin consists of an internship and on the job training (OJT). OJT is a program that aims to provide work experience for students and understanding the work environment in the industry. In AKA, students also prepare an internship report together with the OJT. Internship report contains the research to solve a problem scientifically or perform daily routine activity analysis in place of internship with material according to field of study program [22]. The students who have undergone industrial work practices will be evaluated by the teacher/lecturer and industry.

For the simulation, all education institution have teaching factory to give students an experience to make products and analyze the product. SMAKS have activities in analytical services and manufacturing of products related to chemical processes, while AKABO has activity making chemical reagent which inserted in the engineering of chemical separation practice and calibration of laboratory equipment practice [15]. Each of education institutions have products specialization. Teaching factory at SMAKMA is assisted by TVET on its equipment, while AKABO is assisted in the assessment of its teaching factory. 


\section{Micro/product}

At micro level, professionalism of teachers, facilities, and methodology are the main factors that influence of educational results [16]. In correlation with the professionalism of teacher, the strengthening of teaching quality to increase the competitiveness of SMK graduates it is necessary to improve the quality of teaching staff by increasing the proportion of productive teachers [25]. All education institution has $50 \%-70.69 \%$ of productive teacher. Beside their current competency, their competency also developed through internships, attend various training and make scientific writing.

In the area of facilities, all education institutions have classes for learning theory, 8 - 13 laboratories room and it equipment for learning practice and competency test for 4-9 schemes, room for professional certification body (Lembaga Sertifikasi Profesi/LSP) and other supporting facilities. The equipments inside laboratorium have the same or higher level than equipments in industry to support student learning ([12]; [22]; [20]).

Methodology relates to instructional design. This could be explained by using combination of Analysis, Design, Development, Implementation and Evaluation (ADDIE) learning activity and Dick and Carey Instructional Design Model [11].

The most critical problem in the process design of instructional is goals identification. The goals can be identified by defining the knowledge, skills, attitudes, and abilities that must be mastered after students completed a training program [16]. Instructional analysis derived from this goal, while learners and contexts analyzed from student current competencies and motivation. Both used as a basic to write performance objectives at design step.

Performance objectives become the basis for the development of competency based module which consist of an information book, a workbook, and an assessment book as a tool at learning activity.

An evaluation research found a missing-link in the design of polytechnic competence-based curriculum because the lack of evaluation and assessment which has been impacted to educational process and its result [16]. Therefore, assessment instrument need to develop to meet the instructional goal. At AKABO and SMAK, assessment instrument has been designed inline with instructional goal which based on standard and framework regulation. Variety of the testing and measurement instruments such as criterion-reference test, behavior test, practice test of productive subjects all designed and included in the workbook and assessment book.

Formative and summative evaluations implemented at educational institutions measure students' knowledge, skills and attitudes based on standards and framework regulation which has been recognized by industry. So all the stages from analysis, design, development, implementation, to evaluation are on the same framework because using the same source as reference. This implementation answers the lack of evaluation which has been found as a missing link in the design of polytechnic competence-based curriculum

In order to maximize the implementation of competency evaluation, the competence infrastructure must be fulfilled. All education institutions have firstparty certification bodies (LSP pihak pertama/P1), place of competency assessment (Tempat Uji Kompetensi/TUK), sufficient number of assessors and test scheme to meet the needs of the industry.

Types of formative evaluation used at education institution is one-to-one evaluation for competency scheme test, small-group evaluation for all subjects, field-trial evaluation for industrial working practices. For one-to-one evaluation using the workbook in module based competencies.

In order to facilitate the summative evaluation, the semester exam is combined together with the competency test using assessment book conducted at SMAKPA and SMAKBO. At the end of the vocational learning the participants take the skills competency exam consisting of vocational practice exams and vocational theory examinations. Students will have school/college certificate and competency test certificate after they finish and successfully doing their examination.

In order to fulfill one of the goals of the first reposition, international recognition of student competence is required. Therefore SMAK cooperate in joint testing with international institutions such as Vapro and Hobart Institute Technology Australia ([12]; [22]; [21]; [20]).

\section{Process}

The process of learning in schools needs to be supported by various things so that the quality of education and production expectations are met. Curriculum based competencies need to be supported some things as follows :

1) Industry visitation, which the purpose of this activity is for students to know the industry before they learning various materials needed to work in the industry

2) Seminar/workshop/training from an expert (expert day) which the students will have certificate after they follow it ([12]; [22]; [21]; [20]).

\section{3) Management system}

Educational institutes like schools, universities, and training centers are expected to perform at high level, provide quality services and behave professionally. To answer this challenge, all education institution has ISO 9001: 2015 certification, while SMAKPA also certified ISO 17025: 2015 related to laboratory competence standards and get award at national and international level. In addition, AKABO gained an A accreditation from National Accreditation Agency for Higher Education and so did SMAKPA 
from National Accreditation Agency for Schools and Madrasahs.

4) Exchange of students / students and lecturers / teachers with overseas schools / universities

Since 2015 SMAKPA conducts teacher and student exchange programs with vocational secondary school in Thailand, Malaysia and China including apprenticeship program in industry [12].

\section{5) Relationship with alumni.}

Graduates who already work, monitored and still cooperate with the school in an association. Alumni have a role in connecting schools as connector catalyst [26] such as providing recruitment information, giving information on prakerin, giving public lectures for alumni who have occupied manager positions, helping teachers to connect with management when they visit to their workplace and helping to find a place to live for students who are undergoing prakerin.

\section{E. Input}

Input is all resources needed in the education process. Some components which categorized as input such as money, facilities, equipment, supplies, staff, technical expertise [23] and required competencies of the student. Money and facilities could be obtained from public and/or private institution.

\section{CONCLUSION}

Collaboration between academia and industry is increasingly a critical component of efficient national system. By strengthening connections between education providers and private enterprises, it helps equip students with skills needed for successful employment. High employment of vocational graduates is one indicator of education outcome. To meet this outcome, education could be designed using an educational result chain. This tool connect the five organizational elements from mega/outcome, macro/outputs, micro/product, process and input.

Collaboration with industry pattern spread over for organizational elements except the input because resources come from state and international institution. The shape of collaboration can be described as follows :

1) Mega/outcome : National competency standard (SKKNI) formation

2) Macro/outputs : Curriculum based competencies design and review, production based curriculum (industrial working practices, teaching factory) design, implementation and review

3) Micro/product: Teacher/lecturer internship

4) Process : Industry visitation, seminar, training, workshop, relationship with alumni who work in industry, employee competency test, and joint research and publication

To meet the need for recognition of IQF, some materials that have been followed in SMK SMAK also recognized by $\mathrm{AKABO}$ a total of 20 credits.

\section{RECOMMENDATION}

1. Collaboration with pattern educational result chain using SKKNI basis can use the form of this research as the development of IQF basis which has been discussed by Handayani (2014).

2. There is still no mutual recognition of the curriculum between SMK and Polytechnic in Indonesia. The recognition of curriculum between SMK and other polytechnics that have the same specialization can be done on mutually agreed terms and will have a greater impact if established by policymakers. If this goes, it can reduce the cost of college operations and accelerate the availability of graduates ready to work because of the reduced period required in the learning process.

3. Missing link that occurs in the polytechnics curriculum design because the lack of evaluation and assessment tool can be eliminated if the overall stages in the instructional design model are made and refer to the same base, such as SKKNI discussed in this research or other standard used by graduate users.

4. Some activities that help the learning achievement process can be developed as follows : industry visitation, expert day, management system, exchange of students/teacher, relationship with alumni

\section{REFERENCES}

[1] Decree of the Minister of Industry No. 490/MIND/Kep/8/2016 on Guidelines for Development of Polytechnic Industry-Based Competencies that Link and Match with Industry

[2] Decree of the Minister of Industry No. 491/MIND/Kep/8/2016 on Guidelines for Development of Vocational High School Industry based Competencies that Link and Match with Industry

[3] Decree of the Secretary General of the Ministry of Industry No. 81/SJ-IND/Kep/12/2012 Curriculum Vocational High School- SMAK within the Ministry of Industry

[4] Decision of the Director General of Primary and Secondary Education Number 130/D/KEP/KR/2017 on Curriculum Structure of Basic and Secondary Education

[5] Decision of the directorate general of primary and secondary education number 330/D.D5/KEP/KR/2017 dated June 9, 2017 on core competence and basic competence of national content subjects, cantonal content, basic areas of expertise, foundation of skill program, and competence of expertise

[6] E, di Gropello, A. Krusie, P. Tandon, "Skills for the Labor Market in Indonesia : Trends in Demand, Gaps and Supply", The World Bank: Washington DC, 2011, pp.179.

[7] H. Nassaji (2015). Qualitative and descriptive research: Data type versus data analysis. Language Teaching Research. 19. 129-132. 10.1177/1362168815572747.

[8] International Finance Corporation, Private Provision of Education : Opportunities for Emerging Markets, EMCompass, Note 32, February 2017

[9] J. Guimon, Promoting University-Industry Collaboration in Developing Countries, The World Bank: Washington DC, 2013.

[10] L.Scott Safrit, "The Intersection of Academia and Industry : Avoiding Pitfalls and Navigating Successful Partnerships “(doctor's dissertation), University of North Carolina: Chapel Hill, USA, 2014. 
[11] L. Weas. 2012. An Introduction to The Dick \& Carey Instructional Design Model [PowerPoint presentation]. Retrieved from iPay TechnologiesLearning \& Development. https://www.slideshare.net/larryweas/an-introduction-to-thedick-amp-carey-instructional-design-model

[12] M. Nasir, Head of SMK SMAK Padang Report in Graduates Inauguration TP 2016/2017

[13] M. Perkmann, A. Neely, and K. Walsh. 2011. "How Should Firms Evaluate Success in University-Industry Alliances? A Performance Measurement System.” R\&D Management $41 \quad$ (2): $\quad 202-216 . \quad$ doi:10.1111/j.14679310.2011.00637.x

[14] Ministry of Education and Culture. (2017). Industrial working practices guidelines. Jakarta, Indonesia : Directorate of Vocational Secondary School (SMK) Development.

[15] Ministry of Industry, Development of Vocational High School Industry based Competencies that Link and Match with Industry (Ministry of Industry, 2016)

[16] P. Handayani, Finding the Missing Link in the Design of Polytechnics Competence-Based Curriculum. Retrieved from http://www.muhlenberg.edu/library/reshelp/apa_example.pdf

[17] Regulation of Minister of Research, Technology, and Higher Education Republic of Indonesia Number 44 of 2015 on Higher Education National Standards

[18] R. Axelsson, S. and Bihari Axelsson, "Integration and collaboration in public health - a conceptual framework",' In J Health Plann Mgmt 2006; 21: 75-88.

[19] R. Kaufman, J.Herman \& K.Watters, Educational Planning. Strategic, Tactical, and Operational, 2002.
[20] S. Novalia, C. Bachtiyar, Mursiti, N. Muhammad, A.S. Gani, M. Nadar (private communication).

[21] SMAK Makassar, "SMAK Makassar (as supplied 21 and 22 Mei 2018)", unpublished

[22] The Center of Industrial Education and Training (CIET), "Dual system Kapusdiklat 2018 book materials (as supplied 24 Mei 2018)", unpublished

[23] World Bank Group. 2007. Module 2: Result Chain [PowerPoint presentation]. Retrieved from Europe and Central Asia Region and World Bank Institute Evaluation Group.

http://siteresources.worldbank.org/INTUKRAINE/Resources/ 328335-1212401346836/Module2ResultsChainEng.pdf

[24] Yoto. 2017. "Preparing skilled labor in industry through production-based curriculum approach in vocational high school.” AIP Conference Proceedings 1887, 020002 (2017); doi: 10.1063/1.500348

[25] Yulius, M. Isran, M. WP, and B. Anugerah, Roadmap of Vocational Development Policy in Indonesia 2017 - 2025, Coordinating Ministry of Economic Affairs, 2017, pp. 4, 8, 10

[26] https://www.unlockingnetworks.org/wpcontent/uploads/2018/04/handbook-Roles-of-people-innetworks.pdf

[27] http://www.kemenperin.go.id/kompetensi/skkni_idx.php

[28] https://komunika.tempo.co/read/news/2015/06/12/273674446 /smk-program-4-tahun-lebih-disukaiindustri\#.Ww1hFDSFPMx 